\title{
DANDY WALKER SYNDROME: UNSTEADY GIRL WITH MRI FINDINGS
}

\author{
MD ROBED AMIN ${ }^{1}$, MOHAMMAD RAFIQUL ISLAM ${ }^{2}$
}

A female patient of age 13 years was brought to the department of medicine with the complaints of gradually progressive unsteadiness \& weakness of left side of the body for 18 months. No history of headache, fever, convulsion, irritability or drowsiness. Her milestone of development in childhood was normal. According to mother Tania's mental, social
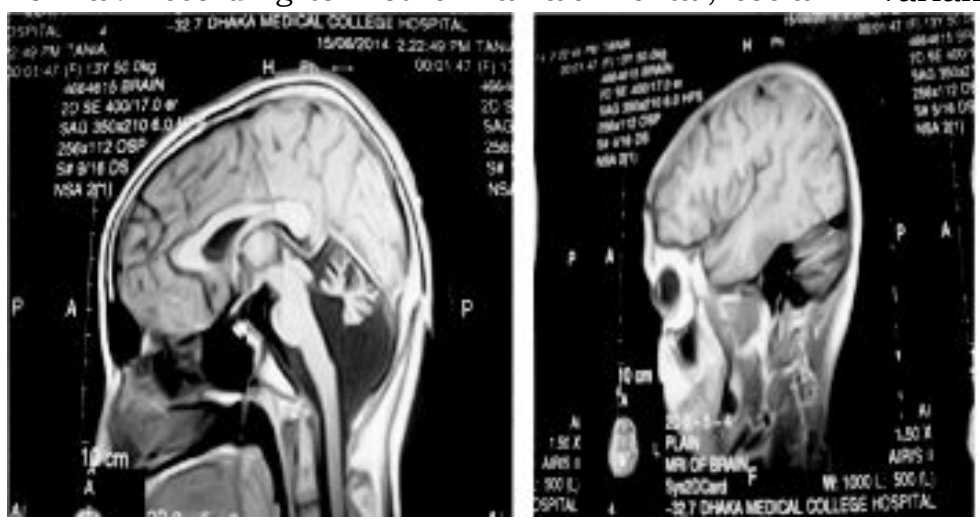

ventricle. There was an associated mild hypoplasia of the cerebellar vermis and folia, the posterior fossa was not enlarged, there is neither dilatation of occipital horns of lateral ventricles (colpocephaly) nor agenesis of corpus callosum. These findings thus paved to the diagnosis of Dandy-Walker variant.

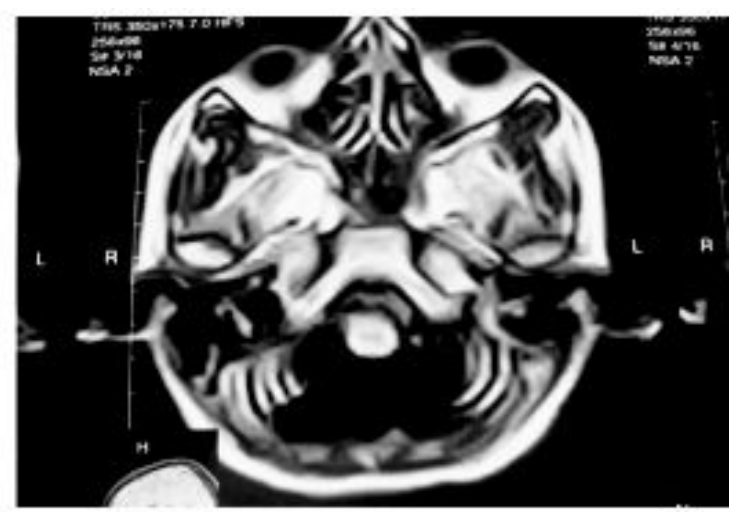

Fig 1(a, b , c): MRI of brain showing cerebelar hypoplasia with absent colpocephaly (Dandy walker Syndrome)

\& emotional development is also normal. Tania was born at term and was the third child of nonconsanguineous parents and the only affected case in the family. Her mother did not give any history of abortion or still birth or child death.

On examination her GCS was 15, Mini mental State Examination revealed 30/30 .Stance \& gait apparently normal but tandem gait showed ataxia. Speech is normal (no dysarthria). Cranial nerves are intact including fundus. Muscle bulk below average in both upper \& lower limbs. Muscle power 4/5 in both upper $\&$ lower limbs. Superficial \& deep tendon reflexes are normal. No pendular jerks. All sensory examinations were normal. Finger nose test, dysdiadokokinesia is normal while heel shin test showed left sided dysmetria.

Study of the MRI of Brain revealed a well-defined extra axial cystic lesion in the posterior fossa in the midline communicating with the fourth

\section{Discussion}

Through the use of modern diagnostic tools (e.g., ultrasound, CT, MRI, etc.), DWM is typically diagnosed in individuals before one year of age ${ }^{1}$. Technical developments in imaging, such as in three-dimensional sonography and magnetic resonance, allow higher resolution and multiplanar images for an easier diagnose .Adult cases of DWM for instance are usually diagnosed incidentally by neuroimaging methods or after minor head trauma as diagnosed in the present case $\mathrm{e}^{2,3}$

\section{References}

1. Osenbach RK, Menezes AH. Diagnosis and management of the Dandy-Walker malformation: 30 years of experience. Pediatr Neurosurg. 1992; 18: 179-89.

2. Engelhard HH, Meyer JR. Adult-onset presentation of Dandy-Walker variant in siblings. Surg Neurol. 1995; 44:43-7.

3. Sato K, Kubota T, Nakamura Y. Adult onset of the dandyWalker syndrome. Br J Neurosurg. 1996; 10: 109-12.

1. Associate Professor of Medicne, Dhaka Medical College

2. Assistant Professor of Medicine, Dhaka Medical College

Address of Correspondence: Dr. Md. Robed Amin 